\title{
Epigenetics Mechanisms in Insects: A Review
}

\author{
U. Pirithiraj ${ }^{1}$, R. P. Soundararajan ${ }^{2} *$ and C. Gailce Leo Justin ${ }^{1}$ \\ ${ }^{1}$ Anbil Dharmalingam Agricultural College and Research Institute, \\ Tiruchirappalli-620 027, India \\ ${ }^{2}$ Horticultural College and Research Institute (Women), Tiruchirappalli-620 027, India \\ *Corresponding author
}

\section{A B S T R A C T}

K e y w o r d s
Epigenetics, Insects,
DNA methylation,
Histone
modification and
RNAi

Epigenetics is the study of heritable changes in gene expression that do not involve changes in the underlying DNA sequence (or) a change in phenotype without a change in genotype. Phenotype is the observable or measurable characteristics of an organism i.e., height, behaviour, colour, shape, and size. Insects are being examined for their epigenetic phenomena and the underlying mechanism behind it. Epigenetics is well studied in fruit fly, Drosophila melanogaster. Gene is segments of the DNA sequence that store the information to synthesize proteins or RNAs that carry out specific functions. Epigenetics is important in cellular differentiation which is responsible for the phenotypic plasticity. Epigenetics is been investigated in plants and animals. On comparing other organisms insects possess a high degree of phenotypic variation. This variation is due to switch on and off mechanism of gene. Gene expression and repression in insects is regulated through epigenetic mechanisms i.e. DNA Methylation, Histone modification and Noncoding RNAs which influence the phenotypic modification. In recent days insects are used as models in studying epigenetics. RNA interference (RNAi), also known as RNA silencing, refers to a set of molecular processes in which noncoding RNA molecules target and silence the expression of specific nucleic acids. Silencing Dnmt3 expression in newly hatched honeybee larvae mimics the effect of royal jelly, namely, the larvae destined to become workers develop into queens with fully developed ovaries. The detailed mechanisms of epigenetics in insect were discussed in the paper.

\section{Introduction}

The growing population and degrading environment are two major problems at international level. Satisfying the growing population's requirement is somewhat difficult. Although there were legal and social constrains in utilizing the biotechnology researches in field level, these tools improve agriculture and human life to a great extent
(Ahmad et al., 2012). Genetically modified mosquitoes created possibilities for controlling diseases like malaria (Catteruccia et al., 2003).

In 1994, the "flavr savr" (first GM tomato) was commercialized (Yang et al., 2005). Bt cotton was the first GM crop approved for use in India (Kapur et al., 2010). Almost in the entire living organism's gene-modification 
plays an important role in developing transgenic organisms. In an organism genes are controlled by some Non-gene mechanisms. The expression and repression of gene without change in respective DNA sequence occurs in all living organisms. Ultimately their study is called epigenetics. Similar to genetic engineering this study leads to a profitable/beneficial research outcome in the science of plant breeding, entomology, pathology, nematology, biotechnology, microbiology, agronomy, soil science etc in various branches of agriculture.

Epigenetics is one of the emerging branch of science yet to be reviewed and more research work has to be carried out for clear cut configuration about the phenotypic plasticity. "Epigenetics term was coined by Conrad $\mathrm{H}$. Waddington in the year 1942". In view of Conrad Waddington, epigenetics is study of epigenesist, i.e. contribution of genotypes to phenotypes during development (Waddington, 1942). According to Arthur Riggs and colleagues it was "the study of mitotically and/or meiotically heritable changes in gene function that cannot be explained by changes in DNA sequence". The study of heritable changes in gene expression that occur without a change in DNA sequence is known as Epigenetics. Without the bullock, the cart cannot be driven. There is "gene" to study for geneticist but no "epigene" for epigeneticist. Epigenetic mechanisms are essential in regulating the genome. Gene expression and repression is regulated by three common mechanisms namely DNA methylation, histone modification, noncoding RNAs occurs in all eukaryotic cells. Additional research works in the recent years are proving the significance of epigenetics in plants, animals and as well as in insects. Many organisms are capable of developing distinct phenotypes from the same genotype (Glastad et al., 2013).Comparing all living organisms in the world insects contribute a high phenotypic plasticity as evident in most of the insects i.e. holometabolous insects having egg, larvae, pupa and adult stages all with same genome. The fruit fly, Drosophila melanogaster is used as a model by the geneticist for studying the biological processes and nothing to get excited, they are preferred for studying epigenetics (Burggren, 2017). Epigenetic inheritance deals with Intra generational and intergenerational epigenetic inheritance. The former is concerned with the development process i.e. how an egg with a single set of genetic instructions is able to develop into a multicellular organism made up of distinct tissues (Waddington, 1942). The later Heard and Martienssen (2014) is concerned with transmission of epigenetic information to offspring. This paper is aimed to describe and understand the basic knowledge on insect epigenetics to the readers.

\section{DNA methylation}

Addition of methyl group to the cytosine in the genes is termed as "DNA methylation". It occurs in all three domains of life Archaea, Bacteria, and Eukarya (Klose and Bird, 2006; Suzuki and Bird, 2008). In insects DNA methylation mostly occur in genes (Glastad et al., 2011) and primarily target the transcription initiation site of genes (Fig. 1). Nearly one half of DNA may be methylated (Glastad et al., 2011; Bewick et al., 2018). The regions where cytosine is followed by guanine are known as $\mathrm{CpG}$ sites or $\mathrm{CpG}$ islands. $\mathrm{CpG}$ methylation is common in eukaryotes (Delcuve et al., 2009). In insects, methylation sites are predominantly restricted to the coding sequence of genes at $\mathrm{CpG}$ sites i.e. pea aphid (Walsh et al., 2010). DNA methylation is highly enriched in exon sequences e.g. Holometabolous insects such as Coleoptera (Cunningham et al., 2015), Hymenoptera (Glastad et al., 2017) and Lepidoptera (Xiang et al., 2010; Hunt et al., 
2013). DNA methylation occurs in larger proportion of the genome e.g. Hemimetabolous insects such as Orthoptera (Wang et al., 2014), Hemiptera (Bewick et al., 2019), Blattodea (Glastad et al., 2016). De novo DNA methyltransferases (Dnmt3 proteins) and maintenance DNA methyl transferases (Dnmt 1 proteins) are the enzymes that facilitate DNA methylation (Lyko, 2018). Gene expression is inhibited by DNA methylation due to interference with DNAbinding transcription factors in promoter regions (Watt and Molloy, 1988).

\section{Low level DNA methylation}

Very low methylation rates of approximately $0.11 \%$ were observed in the genome of the silkworm moth, Bombyx mori, but all of this methylation occurs in $\mathrm{CpG}$ islands (Xiang et al., 2010). In dipteran insects dramatic loss of DNA methylation has been observed, where Dnmt 1 or Dnmt 3 proteins have not detected in the genome sequencing projects (Hung et al., 1999; Tweedie et al., 1999; Marhold et al., 2004). CpG methylation is virtually undetectable in most developmental stages of D. melanogaster due to absence of Dnmts (Zemach et al., 2010).

\section{High level DNA methylation}

Unusually high levels of DNA methylation occur in the desert locust Schistocerca gregaria, which also has an unusually high level of phenotypic plasticity, suggesting DNA methylation involvement in insect polyphenism (Falckenhayn et al., 2013).

Gene specific DNA methylation played a role in mediating insecticide resistance in the hemipteran aphids Myzus persicae (Field et al., 1996; Field et al., 2004) and Schizaphis graminum (Ono et al., 1999). In termites over $12 \%$ of genomic $\mathrm{CpGs}$ and $58 \%$ of exonic CpGs were methylated.

\section{Application}

Epigenetic mechanisms play key roles in adaptation to a changing environment and have been implicated in the regulation of phenotypic plasticity (Moczek and Snell- Rood, 2008). Nemoria arizonaria caterpillars mimic different plants depending on their food uptake (Nijhout et al., 2009). Interest on the role for DNA methylation in insects surged after an experiment reduced expression of dnmt 3 in honey bee larvae and led to a dramatic shift from worker to queen developmental fate (Kucharski et al., 2008).

\section{Histone modification}

The eukaryotic DNA is wrapped around histone octamers, which consist of four different histone proteins, $\mathrm{H} 2 \mathrm{~A}, \mathrm{H} 2 \mathrm{~B}, \mathrm{H} 3$ and $\mathrm{H} 4$. The N-terminal tail of histone protein is post-transcriptionally modified. Histones play important roles not only in regulation of gene expression but also in DNA repairing mechanisms, DNA replication and recombination. Histones are the small basic proteins that together with DNA form chromatin structures in the cell nucleus. Histones are modified at several different amino acid residues and with many different modifications (Lennartsson and Ekwall, 2009). Chromatin arrangement (the level of gene transcription) is relaxed or condensed according to the degree of acetylation, methylation, phosphorylation and/or ubiquitylation of associated histones (Burggren, 2017). Replacement of canonical histone proteins with sequence variants can considerably alter gene expression (Talbert and Henikoff, 2010). Therefore, histone modification and replacement are both important epigenetic modifications across eukaryotes (Fig. 2). Histone proteins may be more directly implicated in the mediation of phenotypic plasticity than DNA methylation (Simola et al., 2013). 


\section{Histone acetylation}

In eukaryotes, an epigenetic process of gene expression is regulated by histone acetylation/deacetylation which is mediated by two enzymes namely histone acetyl transferases (HATs) and histone deacetylases (HDACs). The acetylation of histones by HATs increases DNA accessibility and promotes gene expression, whereas the removal of acetyl groups by HDACs has the opposite effect (Mukherjee et al., 2012). DNA bound to nucleosomes is less accessible to other proteins. For example, transcription factors (eg. RNA polymerase) typically bind only to sites lacking nucleosomes (Bell et al., 2011).

\section{Histone methylation}

Histone methylation in general associated with transcriptional repression (Black et al., 2012). Histone methylation occurs predominantly on histones $\mathrm{H} 3$ and $\mathrm{H} 4$. Histone methylation is commonly targeted at arginine (R) or lysine (K) residues. H3-K9 dimethylation and H3-K27 trimethylation are both associated with heterochromatin formation thus silencing gene expression, whereas H3-K4, H3-K36, or H3-K79 methylation is associated with euchromatin formation (Maison and Almouzni, 2004; Peterson and Laniel, 2004).

\section{Histone phosphorylation}

Histone phosphorylation is mediated via protein kinases (which adds phosphate groups) and protein phosphatases (which removes phosphate groups) (Ellenbroek and Youn, 2016). All core histones contain phosphoracceptor sites in their N-terminal domains: H2A is phosphorylated on Ser1, H2B on Ser14 and Ser32, H3 on Ser10 and Ser28, H4 gets phosphorylated on Ser1 (Loury and Sassone-Corsi, 2003).

\section{Histone ubiquitination}

Histone ubiquitination is a modification mediated by the attachment of ubiquitin (Ub), which is a 76-amino acid protein that is ubiquitously distributed and highly conserved throughout eukaryotic organisms (Kerscher $e t$ al., 2006; Zhang et al., 2018).

\section{Histone variants}

Replacement of canonical histone proteins with sequence variants can considerably alter gene expression. Key histone variants are conserved between insects and mammals and are also linked to gene regulation in Drosophila Specifically, H2A variants increase the mobility of, or destabilize, the nucleosomes in which they are found, resulting in increased accessibility of DNA (Talbert and Henikoff, 2010). In invertebrates histone H2A.v (H2A.Z in vertebrates) is a variant of the canonical histone H2A (Baldi and Becker, 2013).

\section{Applications}

Studies have been made on histone acetylation/deacetylation in associated with regulation of pupal diapause in the flesh fly, Sarcophaga bullata (Reynolds et al., 2016). Histone-modifying enzyme systems are differentially expressed in brain tissues of solitarious and gregarious migratory locusts Locusta migratoria, although the varying gene expression leads to the gregarious and solitorius phase changes which results in their different phenotype (Guo et al., 2015).

Suppression of histone deacetylases (HDAC) by injection of HDACi (inhibitor) or small interfering RNAs (siRNAs) against the HDAC encoding gene Rpd3 into young soldier's brain induce and sustain forager-like activity and scouts for up to 50days in ant, Camponotus floridanus. 


\section{RNA interference}

RNA interference (RNAi), also known as RNA silencing, refers to a set of molecular processes in which non-coding RNA molecules target and silence the expression of specific nucleic acids (Ha and Kim, 2014). The core components of RNAi pathways are Argonaute proteins, which associate with the sRNAs and silence specific target nucleic acids (Meister, 2013). The Argonaute and sRNA complex is termed the RNA induced silencing complex (RISC).

Non-coding RNAs are transcribed from DNA but, rather than being translated into protein, instead regulate gene expression at both transcriptional and post-translational levels. There are Types of ncRNAs reported in insects that include microRNAs (miRNA), small interfering RNAs (siRNA), PiWi interacting RNAs (piRNA), long noncoding RNAs (lncRNA), architectural RNAs (arcRNA) and circular RNAS (circRNA) (Abu and Jamal, 2016; Beermann et al., 2016; $\mathrm{Ng}$ et al., 2016; Chujo et al., 2017; Hanan et al., 2017; Sas-Chen and Schwartz, 2019). The evidence that piRNAs and IncRNAs have epigenetic effects is particularly strong in insects (Chambeyron and Seitz, 2014) (Fig. $3)$.

\section{P-element Induced WImpy testis or PiWi interacting RNAs (piRNA)}

piRNAs are highly variable, short (21-35 nucleotides), single-stranded ncRNAs that can initiate epigenetic effects within insect genomes. piRNAs were first identified in D. melanogaster. piRNAs act to silence TEs and therefore prevent harmful TE-induced mutations. Target repression by piRNAs also comes in two forms: transcriptional gene silencing (TGS) and post-transcriptional gene silencing (PTGS). In Nucleus PIWI proteins are guided by piRNAs to nascent transposon and generate heterochromatin via DNA or histone methylation, thus silencing transcription. In the cytoplasm, piRNAs elicit post-transcriptional silencing by directing PIWI proteins to slice target transcripts (Ozata et al., 2019).

\section{Autoamplifying biogenesis pathway or 'ping-pong loop'}

piRNAs are produced in additional germ line cells, called 'nurse cells' then deposited in the oocyte. Deep-sequencing of Drosophila ovarian piRNAs revealed that piRNAs tend to be complementary to each other throughout their first 10 nucleotides. A mature piRNA guides the cleavage of a complementary piRNA precursor, thus contributing to the maturation of another piRNA (Bonasio, 2012; Dowling et al., 2016). piRNA Pathway Genes in Drosophila melanogaster involves three Argonaute proteins of the Piwi family (Argonaute3, Piwi, and Aubergine) (Dowling et al., 2016). Argonaute-3 loaded piRNAs frequently have an adenosine at position 10 . Aubergine loaded piRNAs tend to have a uridine at their 50 -most position, while Argonaute-3 loaded piRNAs are usually in the sense orientation. Aubergine loaded piRNAs are usually antisense to the transposon sequence (Chambeyron and Seitz, 2014).

\section{Micro RNA}

The first miRNA, lin-4 from Caenorhabditis elegans, was discovered by Ambros and coworkers in 1993 as an endogenous regulator of genes that control developmental timing (Ambros, 2003). miRNA Pathway Genes - Argonaute1, Dicer1, Loquacious, Drosha, and Pasha (Obbard et al., 2009). In fruit fly, Drosophila Dicer-1 is required for miRNA biogenesis, whereas Dicer-2 is devoted mostly to the siRNA pathway (Tomari and Zamore, 2005). 
The molecular evidence that miRNAs influence chromatin or passed down through cell divisions in a truly epigenetic manner is still lacking in insects (Lim and Brunet, 2013; Chambeyron and Seitz, 2014).

\section{Small interfering RNA}

The siRNA pathway is found throughout insects (Dowling et al., 2016).siRNAs may be associated with the transmission of epigenetic information in insects. siRNAs are loaded into the RNA-induced transcriptional silencing complex (RITSC). The RITSC then binds to the specific genomic target which results in heterochromatin formation (Castel and Martienssen, 2013). siRNAs may affect $X$ chromosome inactivation in Drosophila (Koya and Meller, 2015).

\section{Long non-coding RNAs}

lncRNAs represent a broad category of RNAs that are over 200 nucleotides long and not translated into proteins (Bonasio and Shiekhattar, 2014). IncRNAs can bind to specific targets and recruit chromatinmodifying enzymes, initiating the formation of a silent or active chromatin state (Fatica and Bozzoni, 2014).

\section{Applications}

RNAi plays an important role in regulating gene expression in eukaryotes. Genetically modified Arabidopsis and tobacco plants expressing double standard RNA were tend to resist bollworms. The expression of dsRNA in cotton plants is targeted at P450 gene, CYP6AE14 in the bollworm (Helicoverpa armigera). Boll worms reared on the plants containing dsRNA showed retarded growth due to toxification of gossypol. dsRNA treated rice varieties TN1 and PTB33 were observed with low population of brown plant hopper, Nilaparvata lugens when comparing untreated plants.

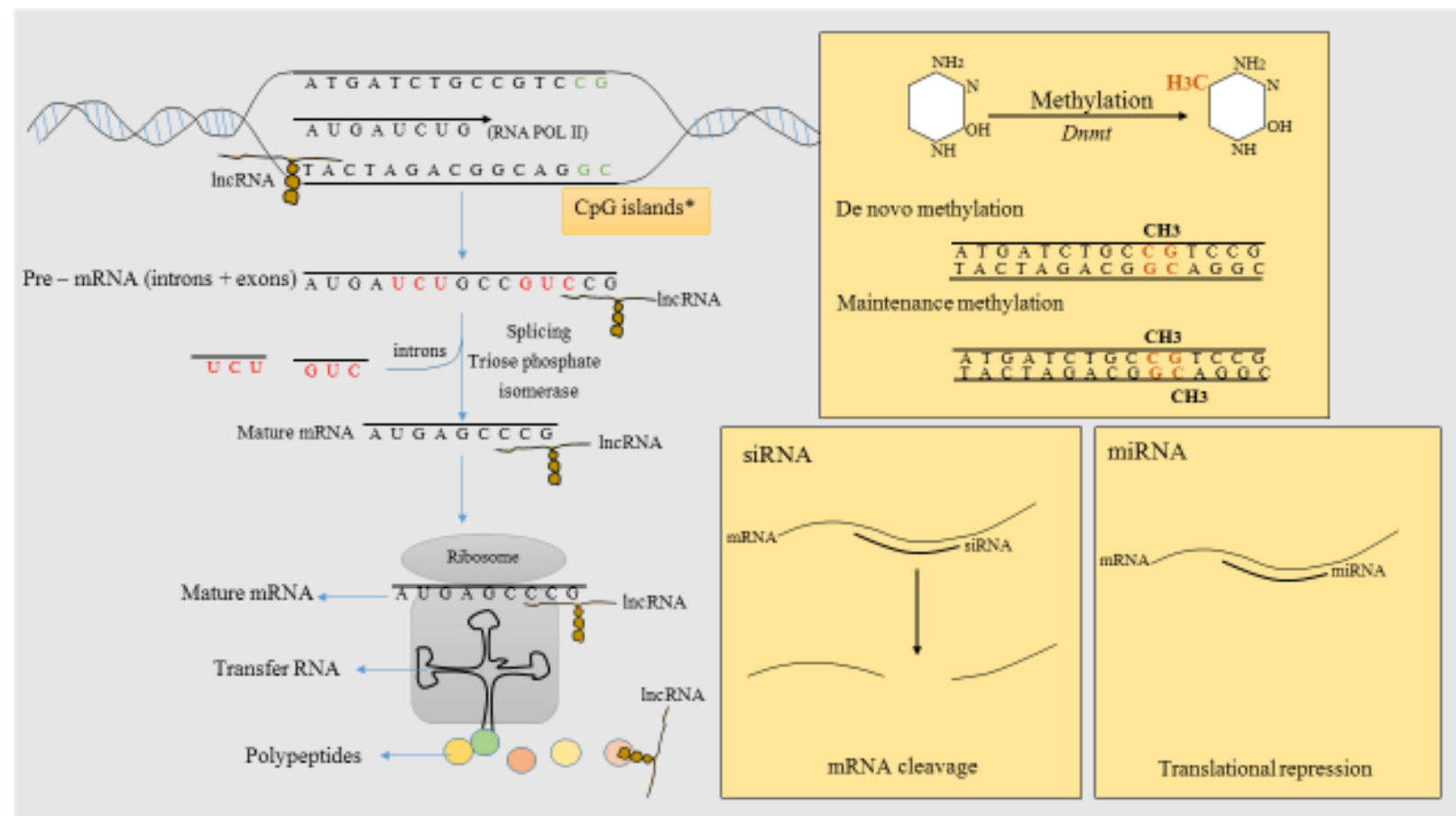

Fig.1 DNA methylation at $\mathrm{CpG}$ sites, functions of long non coding RNA, Role of siRNA and miRNA 
(a)

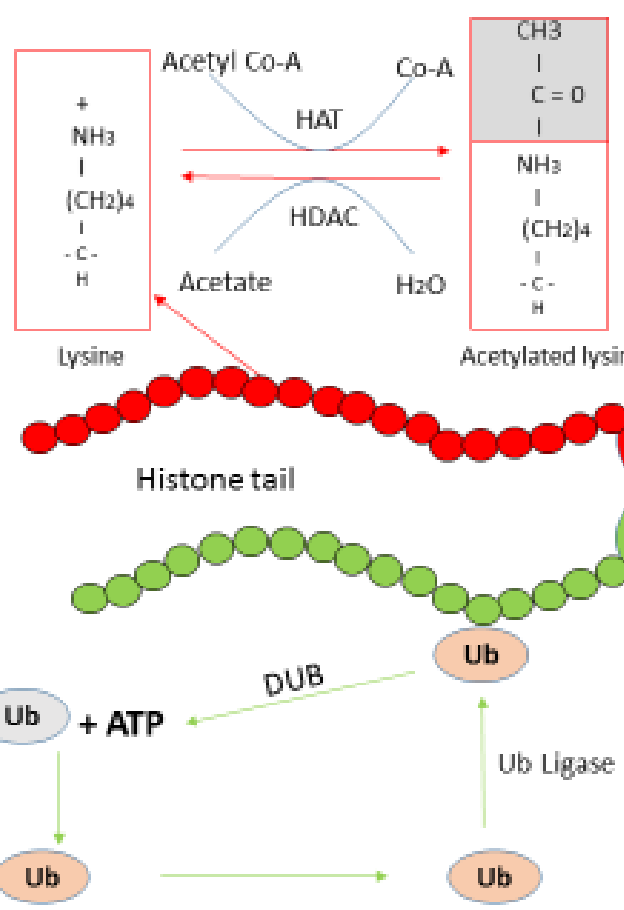

DU8-Deubiquitinating enzyme

(b)

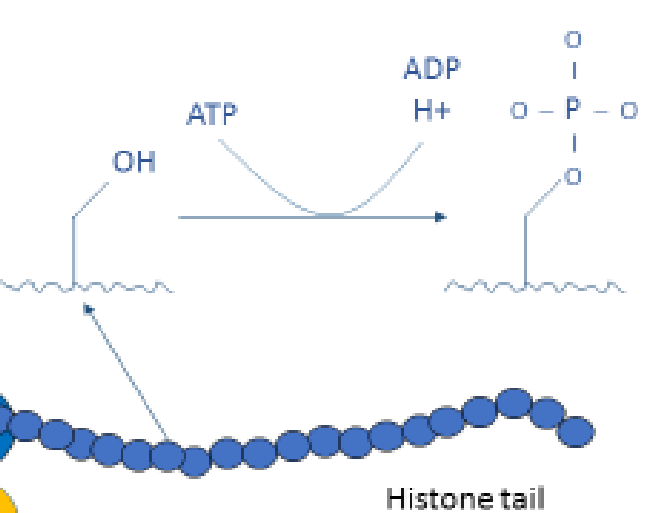

н3

H4

(d)

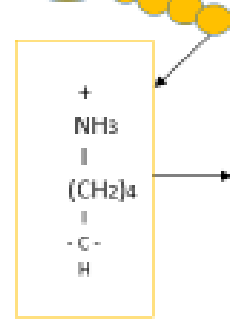

Lysine
Histone tail

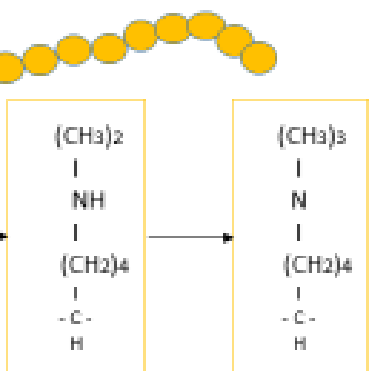

Di-methylated

Tri-methylated

Fig.2 (a) Histone acetylation (b) Histone phosphorylation (c) Histone ubiquitination (d) Histone methylation

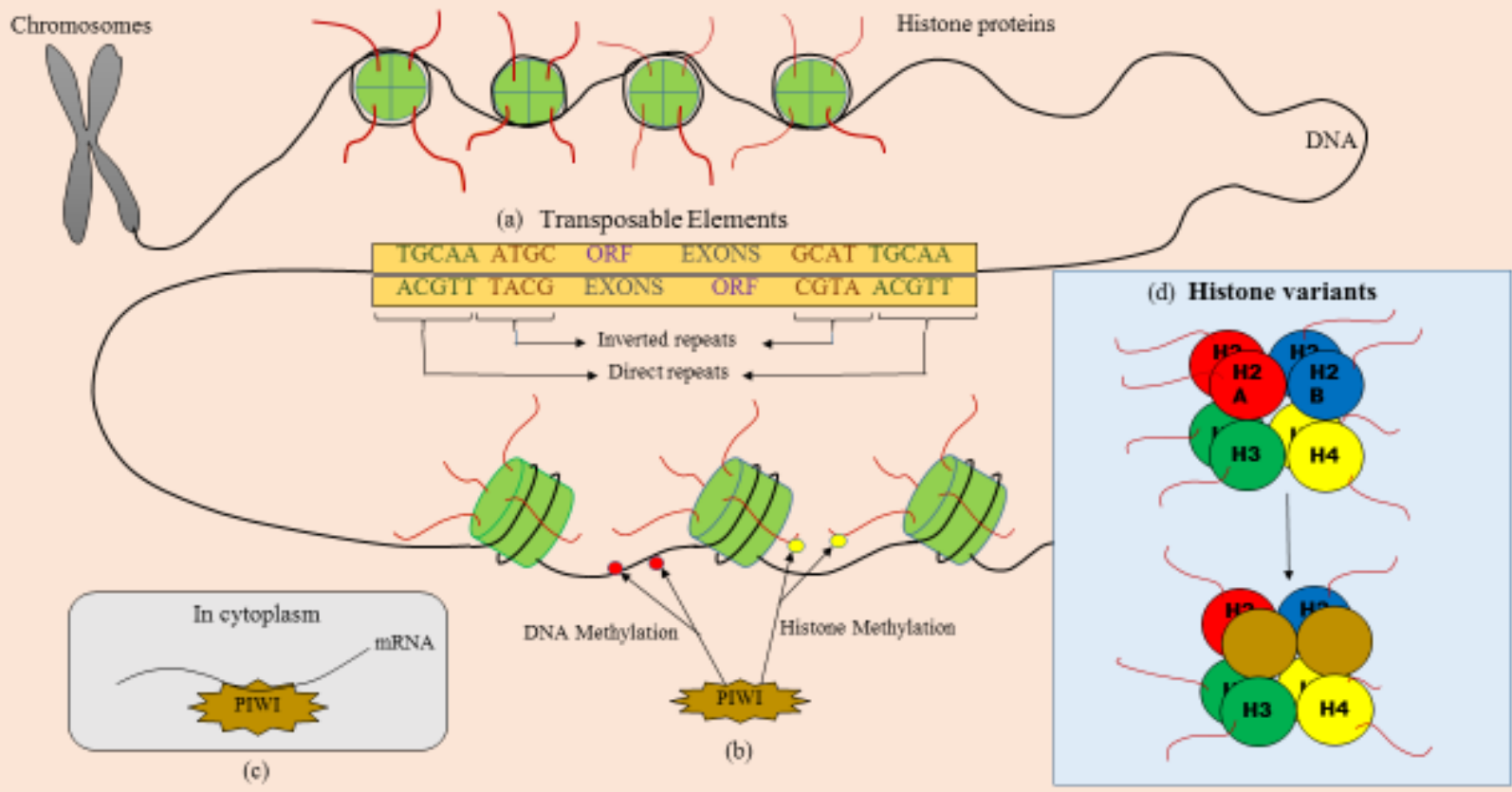

Fig.3 (a) Structure of jumping genes (b) PIWI interacting RNA induced DNA methylation and Histone methylation (c) PIWI interaction with mRNA in cytoplasm (d) Histone variation 
Epigenetic studies opens up a new path to walk faraway from our imaginations. Managing insect population without affecting natural environment is a crucial factor in agriculture. Imparting the knowledge on epigenetic to pest management will provide new management tactics. Management of major pests like $\mathrm{BPH}$ in rice, $H$. armigera in cotton are some of the proven examples. From our ancient historic periods, humans started domesticating animals, rearing insects for their purpose. There are types of methods for queen rearing but still development of queens form larvae of honey bees through epigenetics are astonishing. Studying epigenetics in insects gives knowledge on rearing/domesticating them, changing their phenotypic diversity as well as in their management. A clear understanding of epigenetics is still wanted for the human life to fulfill the next generation requirements.

\section{Acknowledgement}

We acknowledge all coted authors in this particular new science and their reference works were cited in this article. Most of the cited references are review papers instead of original report due to the broad nature of the topic. We thank our Institute Dean, ADACRI, TNAU, Trichy, India for his encouragement to prepare the manuscript.

\section{References}

Abu, N., and Jamal, R. (2016). Circular RNAs as promising biomarkers: a mini-review. Frontiers in Physiology, 7, 355.

Ahmad, P., Ashraf, M., Younis, M., Hu, X., Kumar, A., Akram, N. A., and Al-Qurainy, F. (2012). Role of transgenic plants in agriculture and biopharming. Biotechnology Advances, 30(3), 524-540.

Ambros, V. (2003). MicroRNA pathways in flies and worms: growth, death, fat, stress, and timing. Cell, 113(6), 673-676.

Baldi, S., and Becker, P. B. (2013). The variant histone H2A. V of Drosophila-three roles, two guises. Chromosoma, 122(4), 245-258.

Beermann, J., Piccoli, M. T., Viereck, J., and Thum, T. (2016). Non-coding RNAs in development and disease: background, mechanisms, and therapeutic approaches. Physiological Reviews, 96(4), 1297-1325.

Bell, O., Tiwari, V. K., Thomä, N. H., and Schübeler, D. (2011). Determinants and dynamics of genome accessibility. Nature Reviews Genetics, 12(8), 554.

Bewick, A. J., Sanchez, Z., Mckinney, E. C., Moore, A. J., Moore, P. J., and Schmitz, R. J. (2018). Gene-regulatory independent functions for insect DNA methylation. BioRxiv, Pp. 355-669.

Bewick, A. J., Sanchez, Z., Mckinney, E. C., Moore, A. J., Moore, P. J., and Schmitz, R. J. (2019). Dnmt1 is essential for egg production and embryo viability in the large milkweed bug, Oncopeltus fasciatus. Epigenetics and Chromatin, 12(1), 6.

Black, J. C., Van Rechem, C., and Whetstine, J. R. (2012). Histone lysine methylation dynamics: establishment, regulation, and biological impact. Molecular cell, 48(4), 491-507.

Bonasio, R. (2012). Emerging topics in epigenetics: ants, brains, and noncoding RNAs. Annals of the New York Academy of Sciences, 1260(1), 14-23.

Bonasio, R. and Shiekhattar, R. (2014). Regulation of transcription by long noncoding RNAs. Annual review of genetics, 48, 433-455.

Burggren, W. W. (2017). Epigenetics in insects: mechanisms, phenotypes and ecological and evolutionary implications Advances in Insect Physiology (Vol. 53, pp. 1-30): Elsevier.

Castel, S. E., and Martienssen, R. A. (2013). RNA interference in the nucleus: roles for small RNAs in transcription, epigenetics and beyond. Nature Reviews Genetics, 14(2), 100.

Catteruccia, F., Godfray, H. C. J., and Crisanti, A. (2003). Impact of genetic manipulation on the fitness of Anopheles stephensi mosquitoes. Science, 299(5610), 12251227.

Chambeyron, S., and Seitz, H. (2014). Insect small non-coding RNA involved in 
epigenetic regulations. Current Opinion in Insect Science, 1, 1-9.

Chujo, T., Yamazaki, T., Kawaguchi, T., Kurosaka, S., Takumi, T., Nakagawa, S., and Hirose, T. (2017). Unusual semi- extractability as a hallmark of nuclear body- associated architectural noncoding RNAs. The EMBO Journal, 36(10), 1447-1462.

Cunningham, C. B., Ji, L., Wiberg, R. A. W., Shelton, J., McKinney, E. C., Parker, D. J., Ritchie, M. G. (2015). The genome and methylome of a beetle with complex social behavior, Nicrophorus vespilloides (Coleoptera: Silphidae). Genome Biology and Evolution, 7(12), 3383-3396.

Delcuve, G. P., Rastegar, M., and Davie, J. R. (2009). Epigenetic control. Journal of Cellular Physiology, 219(2), 243-250.

Dowling, D., Pauli, T., Donath,A., Meusemann, K., Podsiadlowski, L., Petersen, M., Peters, R.S., Mayer, C., Liu, S., Zhou, X., Misof, B., Niehuis, O. (2016). Phylogenetic origin and diversification of RNAi pathway genes in insects. Genome Biology and Evolution, 8(12), 3784-3793.

Ellenbroek, B., and Youn, J. U. (2016). Geneenvironment Interactions in Psychiatry: Nature, Nurture, Neuroscience: Academic Press.

Falckenhayn, C., Boerjan, B., Raddatz, G., Frohme, M., Schoofs, L., and Lyko, F. (2013). Characterization of genome methylation patterns in the desert locust, Schistocerca gregaria. Journal of Experimental Biology, 216(8), 1423-1429.

Fatica, A., and Bozzoni, I. (2014). Long noncoding RNAs: new players in cell differentiation and development. Nature Reviews Genetics, 15(1), 7-21.

Field, L., Crlck, S., and Devonshire, A. (1996). Polymerase chain reaction- based identification of insecticide resistance genes and DNA methylation in the aphid, Myzus persicae (Sulzer). Insect Molecular Biology, 5(3), 197-202.

Field, L., Lyko, F., Mandrioli, M., and Prantera, G. (2004). DNA methylation in insects. Insect Molecular Biology, 13(2), 109-115.

Glastad, K., Hunt, B., and Goodisman, M. (2013). Evidence of a conserved functional role for
DNA methylation in termites. Insect Molecular Biology, 22(2), 143-154.

Glastad, K., Hunt, B. G., Yi, S., and Goodisman, M. (2011). DNA methylation in insects: on the brink of the epigenomic era. Insect Molecular Biology, 20(5), 553-565.

Glastad, K. M., Arsenault, S. V., Vertacnik, K. L., Geib, S. M., Kay, S., Danforth, B. N., . . . Hunt, B. G. (2017). Variation in DNA methylation is not consistently reflected by sociality in Hymenoptera. Genome Biology and Evolution, 9(6), 1687-1698.

Glastad, K. M., Gokhale, K., Liebig, J., and Goodisman, M. A. (2016). The caste-and sex-specific DNA methylome of the termite, Zootermopsis nevadensis. Scientific Reports, 6, 37110.

Guo, X., Ma, Z., and Kang, L. (2015). Two dopamine receptors play different roles in phase change of the migratory locust. Frontiers in behavioral neuroscience, 9, 80.

Ha, M., and Kim, V. N. (2014). Regulation of microRNA biogenesis. Nature reviews Molecular Cell Biology, 15(8), 509-524.

Hanan, M., Soreq, H., and Kadener, S. (2017). CircRNAs in the brain. RNA Biology, 14(8), 1028-1034.

Heard, E., and Martienssen, R. A. (2014). Transgenerational epigenetic inheritance: myths and mechanisms. Cell, 157(1), 95109.

Hung, M.-S., Karthikeyan, N., Huang, B., Koo, H.-C., Kiger, J., and Shen, C.-K. J. (1999). Drosophila proteins related to vertebrate DNA (5-cytosine) methyltransferases. Proceedings of the National Academy of Sciences, 96(21), 11940-11945.

Hunt, B. G., Glastad, K. M., Yi, S. V., and Goodisman, M. A. (2013). The function of intragenic DNA methylation: insights from insect epigenomes: Oxford University Press.

Kapur, M., Bhatia, R., Pandey, G., Pandey, J., Paul, D., and Jain, R. K. (2010). A case study for assessment of microbial community dynamics in genetically modified Bt cotton crop fields. Current Microbiology, 61(2), 118-124.

Kerscher, O., Felberbaum, R., and Hochstrasser, M. (2006). Modification of proteins by ubiquitin and ubiquitin-like proteins. Аnnu. 
Rev. Cell Dev. Biol., 22, 159-180.

Klose, R. J., and Bird, A. P. (2006). Genomic DNA methylation: the mark and its mediators. Trends in Biochemical Sciences, 31(2), 89-97.

Koya, S. K., and Meller, V. H. (2015). Modulation of heterochromatin by male specific lethal proteins and roX RNA in Drosophila melanogaster males. PLoS ONE, 10(10), e0140259.

Kucharski, R., Maleszka, J., Foret, S., and Maleszka, R. (2008). Nutritional control of reproductive status in honeybees via DNA methylation. Science, 319(5871), 18271830.

Lennartsson, A., and Ekwall, K. (2009). Histone modification patterns and epigenetic codes. Biochimica et Biophysica Acta (BBA)General Subjects, 1790(9), 863-868.

Lim, J. P., and Brunet, A. (2013). Bridging the transgenerational gap with epigenetic memory. Trends in Genetics, 29(3), 176186.

Loury, R., and Sassone-Corsi, P. (2003). Histone phosphorylation: how to proceed. Methods, 31(1), 40-48.

Lyko, F. (2018). The DNA methyltransferase family: a versatile toolkit for epigenetic regulation. Nature Reviews Genetics, 19(2), 81.

Maison, C., and Almouzni, G. (2004). HP1 and the dynamics of heterochromatin maintenance. Nature reviews Molecular Cell Biology, 5(4), 296.

Marhold, J., Rothe, N., Pauli, A., Mund, C., Kuehle, K., Brueckner, B., and Lyko, F. (2004). Conservation of DNA methylation in dipteran insects. Insect Molecular Biology, 13(2), 117-123.

Meister, G. (2013). Argonaute proteins: functional insights and emerging roles. Nature Reviews Genetics, 14(7), 447-459.

Moczek, A. P., and Snell- Rood, E. C. (2008). The basis of bee- ing different: the role of gene silencing in plasticity. Evolution and Development, 10(5), 511-513.

Mukherjee, K., Fischer, R., and Vilcinskas, A. (2012). Histone acetylation mediates epigenetic regulation of transcriptional reprogramming in insects during metamorphosis, wounding and infection.
Frontiers in Zoology, 9(1), 25.

Ng, K. W., Anderson, C., Marshall, E. A., Minatel, B. C., Enfield, K. S., Saprunoff, H. L., Martinez, V. D. (2016). Piwi-interacting RNAs in cancer: emerging functions and clinical utility. Molecular Cancer, 15(1), 5.

Nijhout, H., Davidowitz, G., Whitman, D., and Ananthakrishnan, T. (2009). Phenotypic plasticity in insects: Mechanisms and consequences. Philos. Trans R.Soc. Lond. Biol. Sci. 365(1540); 593-603

Obbard, D. J., Welch, J. J., Kim, K.-W., and Jiggins, F. M. (2009). Quantifying adaptive evolution in the Drosophila immune system. PLoS Genetics, 5(10), e1000698.

Ono, M., Swanson, J. J., Field, L. M., Devonshire, A. L., and Siegfried, B. D. (1999). Amplification and methylation of an esterase gene associated with insecticideresistance in greenbugs, Schizaphis graminum (Rondani)(Homoptera: Aphididae). Insect Biochemistry and Molecular Biology, 29(12), 1065-1073.

Ozata, D. M., Gainetdinov, I., Zoch, A., Carroll, D., and Zamore, P. D. (2019). PIWIinteracting RNAs: small RNAs with big functions. Nature Reviews Genetics, 20(2), 89-108.

Peterson, C. L., and Laniel, M.-A. (2004). Histones and histone modifications. Current Biology, 14(14), R546-R551.

Reynolds, J., Bautista-Jimenez, R., and Denlinger, D. (2016). Changes in histone acetylation as potential mediators of pupal diapause in the flesh fly, Sarcophaga bullata. Insect Biochemistry and Molecular Biology, 76, 29-37.

Sas-Chen, A., and Schwartz, S. (2019). Misincorporation signatures for detecting modifications in mRNA: Not as simple as it sounds. Methods, 156, 53-59.

Simola, D. F., Wissler, L., Donahue, G., Waterhouse, R. M., Helmkampf, M., Roux, J., Viljakainen, L. (2013). Social insect genomes exhibit dramatic evolution in gene composition and regulation while preserving regulatory features linked to sociality. Genome Research, 23(8), 12351247.

Suzuki, M. M., and Bird, A. (2008). DNA methylation landscapes: provocative 
insights from epigenomics. Nature Reviews Genetics, 9(6), 465.

Talbert, P. B., and Henikoff, S. (2010). Histone variants - ancient wrap artists of the epigenome. Nature reviews Molecular Cell Biology, 11(4), 264.

Tomari, Y., and Zamore, P. D. (2005). Perspective: machines for RNAi. Genes \& Development, 19(5), 517-529.

Tweedie, S., Ng, H.-H., Barlow, A. L., Turner, B. M., Hendrich, B., and Bird, A. (1999). Vestiges of a DNA methylation system in Drosophila melanogaster. Nature Genetics, 23(4), 389.

Waddington, C. H. (1942). Canalization of development and the inheritance of acquired characters. Nature, 150(3811), 563.

Walsh, T. K., Brisson, J. A., Robertson, H. M., Gordon, K., Jaubert- Possamai, S., Tagu, D., and Edwards, O. (2010). A functional DNA methylation system in the pea aphid, Acyrthosiphon pisum. Insect Molecular Biology, 19, 215-228.

Wang X., Qiye L., Jinmin L., Li L., Lijun J., Huimin C., Fei X., Haigang Q., Linlin Z., Fucun W., Jie M., Huayong Q., Xiaodong F., Ximing U. and Guofan Z. (2014). Genome-wide and single-base resolution DNA methylomes of the Pacific oyster Crassostrea gigas provide insight into the evolution of invertebrate $\mathrm{CpG}$ methylation. BMC Genomics, 15(1), 1119.

Watt, F., and Molloy, P. L. (1988). Cytosine methylation prevents binding to DNA of a HeLa cell transcription factor required for optimal expression of the adenovirus major late promoter. Genes and Development, 2(9), 1136-1143.

Xiang, S., Liu, Z., Zhang, B., Zhou, J., Zhu, B.D., Ji, J., and Deng, D. (2010). Methylation status of individual $\mathrm{CpG}$ sites within Alu elements in the human genome and Alu hypomethylation in gastric carcinomas. BMC Cancer, 10(1), 44.

Yang, L., Pan, A., Zhang, K., Guo, J., Yin, C., Chen, J., Zhang, D. (2005). Identification and quantification of three genetically modified insect resistant cotton lines using conventional and TaqMan real-time polymerase chain reaction methods. Journal of Agricultural and Food Chemistry, 53(16), 6222-6229.

Zemach, A., McDaniel, I. E., Silva, P., and Zilberman, D. (2010). Genome-wide evolutionary analysis of eukaryotic DNA methylation. Science, 328(5980), 916-919.

Zhang, Y., Zhang, X., Shi, J., Tuorto, F., Li, X., Liu, Y., Qian, J. (2018). Dnmt2 mediates intergenerational transmission of paternally acquired metabolic disorders through sperm small non-coding RNAs. Nature Cell Biology, 20(5), 535.

\section{How to cite this article:}

Pirithiraj, U., R. P. Soundararajan and Gailce Leo Justin, C. 2020. Epigenetics Mechanisms in Insects: A Review. Int.J.Curr.Microbiol.App.Sci. 9(05): 2961-2971. doi: https://doi.org/10.20546/ijcmas.2020.905.339 